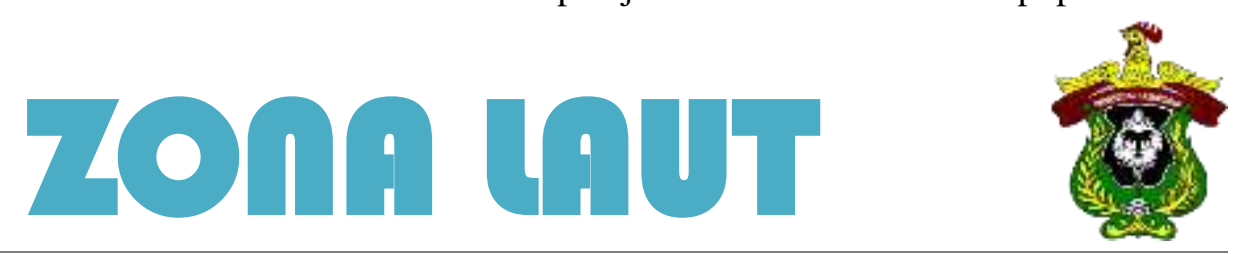

JURNAL INOVASI SAINS DAN TEKNOLOGI KELAUTAN

\title{
REDESAIN RUANG MUAT KAPAL ALIH FUNGSI BARGE MENJADI OIL BARGE 5000 DWT (DEADWEIGHT TONNAGE)
}

\author{
*Urip Prayogi dan Muhammad Khoirul Anwar \\ Program Studi Teknik Sistem Perkapalan Universitas Hang Tuah \\ *prayoginipun@gmail.com
}

\begin{abstract}
Abstrak
Tongkang atau Barge 5000 DWT merupakan sarana atau alat angkutan laut yang memuat batubara. PT Maritim Transportindo tersebut bergerak dibidang industri transportasi perkapalan, yang menyediakan tongkang untuk mengangkut batubara. Berdasarkan permasalahan tersebut akan direncanakan desain ulang oil barge dengan sesuai standart klas BKI. Hasil perencanaan dengan menggunakan metode perhitungan empiris standart BKI Vol II 2016 hasil perencanaan desain ruang muat didapatkan 5 ruang muat dengan masing-masing ukuran ruang muat yaitu ruang muat 1 dan 2 didapat kan panjang $10.980 \mathrm{~mm}$, ruang muat 3 dan 4 didapat kan panjang $12.810 \mathrm{~mm}$, ruang muat 5 didapat kan panjang $10.980 \mathrm{~mm}$.. Berdasarkan perencanaan pada sistem bongkar muat bahwa pompa sistem bongkar muat di dapatkan diameter pipa direncanakan $125 \mathrm{~mm}$ dengan kapasitas 2 pompa utama bongkar muat yaitu $218,382 \mathrm{~m} 3 / \mathrm{hr}$ dengan waktu 2 jam daya pompa utama 14,12 Kw. Kapasitas pompa standby bongkar muat yaitu 109,191 m3/hr dengan daya pompa $7,0628 \mathrm{KW}$.
\end{abstract}

Kata Kunci: Oil Barge, CPO (Crude Palm Oil), Double Bottom.

\begin{abstract}
Barge or Barge 5000 DWT is a means or means of sea transportation that contains coal. PT Maritim Transportindo is engaged in the shipping transportation industry, which provides barges to transport coal. Based on these problems, a redesign of the oil barge will be planned according to the BKI class standards. The results of planning using the standard empirical calculation method of BKI Vol II 2016, the results of the design of the load space obtained 5 loading spaces with each size of loading space, namely loading space 1 and 2 obtained 10,980 mm in length, 3 and 4 load spaces obtained $12,810 \mathrm{~mm}$ in length. , load space 5 is obtained $10,980 \mathrm{~mm}$ in length. Based on the planning of the loading and unloading system, the pump for loading and unloading system has a planned pipe diameter of $125 \mathrm{~mm}$ with a capacity of 2 main loading and unloading pumps, namely $218,382 \mathrm{~m} 3 / \mathrm{hr}$ with 2 hours of main pump power $14,12 \mathrm{Kw}$. The capacity of the loading and unloading standby pump is $109.191 \mathrm{~m} 3 / \mathrm{hr}$ with a pump power of $7.0628 \mathrm{Kw}$.
\end{abstract}

Keyword: Oil Barge, CPO (Crude Palm Oil), Double Bottom.

\section{PENDAHULAN}

Kapal adalah kendaraan pengangkut penumpang dan Tongkang atau Barge merupakan sarana atau alat angkutan laut yang umumnya banyak digunakan untuk mengangkut barang, baik barang padat (kayu log, mesin - mesin), curah (batubara), ataupun cair (minyak mentah/crude oil). Selain untuk alat angkutan laut, tongkang yang telah direkonstruksi atau dimodifikasi banyak digunakan sebagai kapal akomodasi, hotel terapung, dan keperluan lainnya di lokasi proyek di perairan dan laut [1]. Kapal tongkang banyak digunakan sebagai sarana pengangkut hasil bumi diantaranya batu bara, hal ini dipengaruhi oleh keleluasaan yang dimiliki oleh kapal tongkang untuk menyusuri perairan-perairan dangkal seperti sungai. Kemampuan tongkang melewati daerah perairan ini dikarenakan sarat kapal yang relatif pendek, disertai dengan fleksibilitas kapal untuk dibangun cukup panjang dan lebar sehingga mampu mengangkut cukup banyak muatan dalam sekali pengiriman [2]. PT 
Maritim Transportindo tersebut bergerak dibidang industri tranportasi perkapalan, yang menyediakan tongkang untuk mengangkut batubara. Pada era saat ini CPO (crude palm oil) merupakan salah satu industri yang paling berkembang di indonesia, dengan mengetahui hal itu maka PT Maritim Transportindo direncanakan akan mengalih fungsikan tongkang/barge menjadi oil barge untuk mengangkut CPO(crude palm oil). Untuk kondisi tongkang/barge pada konstruksi ruang muat tersebut masih menggunakan single bottom dan single hull, maka tidak bisa digunakan untuk mengangkut CPO(crude palm oil). Menurut IMO No $13 \mathrm{~F}$ dari Annex 1 MARPOL yaitu kapal yang mengangkut muatan cair berbahaya berat 5000 ton atau lebih harus menggunakan double hull dan double bottom[3]. Berdasarkan permasalahan tersebut maka akan direncanakan desain ulang tongkang/barge menjadi oil barge dengan sesuai standart klas BKI. Begitu juga terdapat pada BKI Vol 2 Section 23 untuk kapal bermuatan minyak 5000 DWT atau lebih wajib menggunakan double hull dan double bottom untuk melindungi muatan jika terjadi kebocoran pada tanki[4]. Nantinya akan ada penambahan kontruksi double bottom, double hull dan sistem bongkar muat karena akan digunakan untuk mengangkut CPO (Crude Palm Oil) maka diperlukan sistem perpipaan untuk bongkar muat. Pada penelitian ini penulis akan melakukan desain ulang ruang muat terlebih pada kontruksinya dan sistem bongkar muat untuk mengangkut muatan CPO.

\section{METODE}

Untuk menyelesaikan penelitian ini ada beberapa urutan proses pekerjaan yang harus diselesaikan, alur pengerjaan tersebut dapat dilihat pada gambar 1.

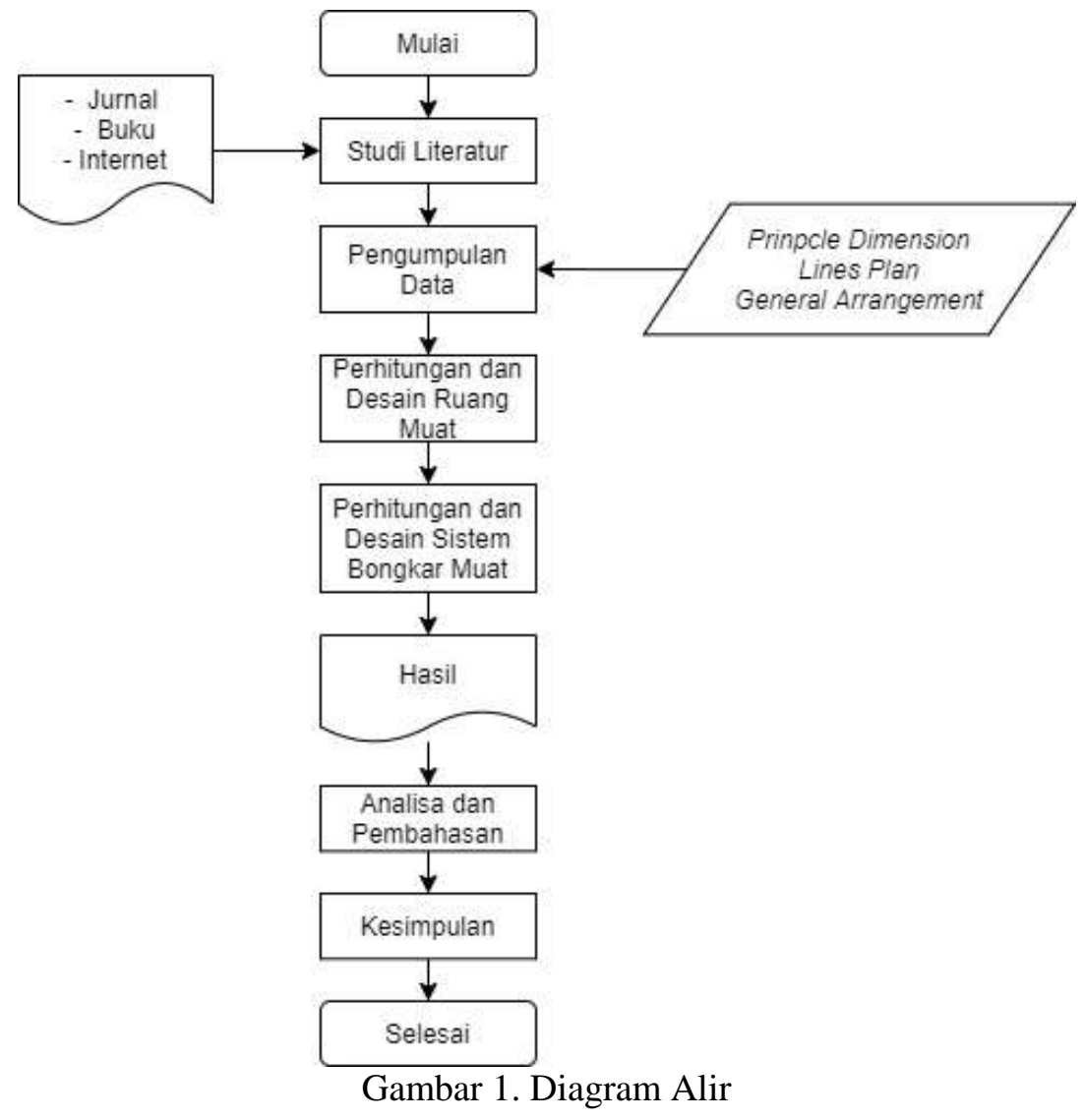

Studi literatur buku dan jurnal terkait mengenai kontruksi ruang muat dan sistem bongkar muat serta perhitungan sesuai standar klas BKI. Pada tahap berikutnya dilakukan pengambilan data dari barge 5000 DWT yang di dapat melalui data studi lapangan di salah satu industri perkapalan di batam. Data yang di dapat tersebut diantaranya adalah mulai dari principle dimension, lines plan dan general arrangement. Data tersebut membantu dalam proses melakukan perhitungan ruang muat dan sistem perpipaan bongkar muat. Setelah dilakukan perhitungan sekat ruang muat dan system bongkar muat yang didapat dari studi literatur maka dilakukan desain ruang muat dan system bongkar muat menggunakan software AutoCAD 2018. 


\section{HASIL DAN PEMBAHASAN}

Dalam penelitian ini data barge yang digunakan sebagai perhitungan dan desain merupakan hasil dari pengamatan data barge yang masih dalam proses pembuatan maupun yang sudah jadi. Data yang digunakan dalam penyusunan penelitian ini sebagai berikut:

Tabel 1. Principle Dimension Oil Barge 5000 DWT

\begin{tabular}{lll}
\hline No. & Data Barge & Dimension $(\mathrm{mm})$ \\
\hline 1 & LOA & 7259 \\
2 & Bmld & 1829 \\
3 & Dmld & 4,88 \\
\hline
\end{tabular}

Setelah data didapat selanjutnya dilakukan perhitungan pembagian sekat ruang muat beserta konstruksi ruang muat. Dari hasil perhitungan mengacu pada BKI Vol II untuk kapal konstruksi double bottom dan double hull, didapatkan ukuran konstruksi ruang muat sebagai berikut:

Tabel 2. Hasil Perhitungan Desain Ruang Muat

\begin{tabular}{lll}
\hline No & Ruang Muat & Hasil $(\mathrm{mm})$ \\
\hline 1 & Ruang Muat 1 dan 2 & 10.980 \\
2 & Ruang Muat 3 dan 4 & 12.810 \\
3 & Ruang Muat 5 & 10.980 \\
\hline
\end{tabular}

Dari hasil perhitungan pembagian sekat ruang muat yang mengacu pada BKI Vol II bahwa untuk panjang dari sekat sudah cukup dan mampu untuk mengangkut crude oil palm sesuai rencana dari pemilik kapal. Sekat kedap diantara pump room dan sekat ruang muat sudah diberikan pada kapal untuk melindungi muatan dan pump room dari kebocoran pada lambung sesuai BKI Vol II section 8. Terdapat juga sekat kedap di belakang pump room memungkinkan untuk melindungi kecelakaan kapal yang berada afterpeak bulkhead yang juga sudah tertera pada BKI Vol II section 8. Setelah dilakukan perhitungan pembagian sekat ruang muat selanjutnya dilakukan desain perencanaan 2 dimensi menggunakan software AutoCAD 2018. Berikut hasil desain perencanaan 2 dimensi dapat dilihat pada gambar 2:

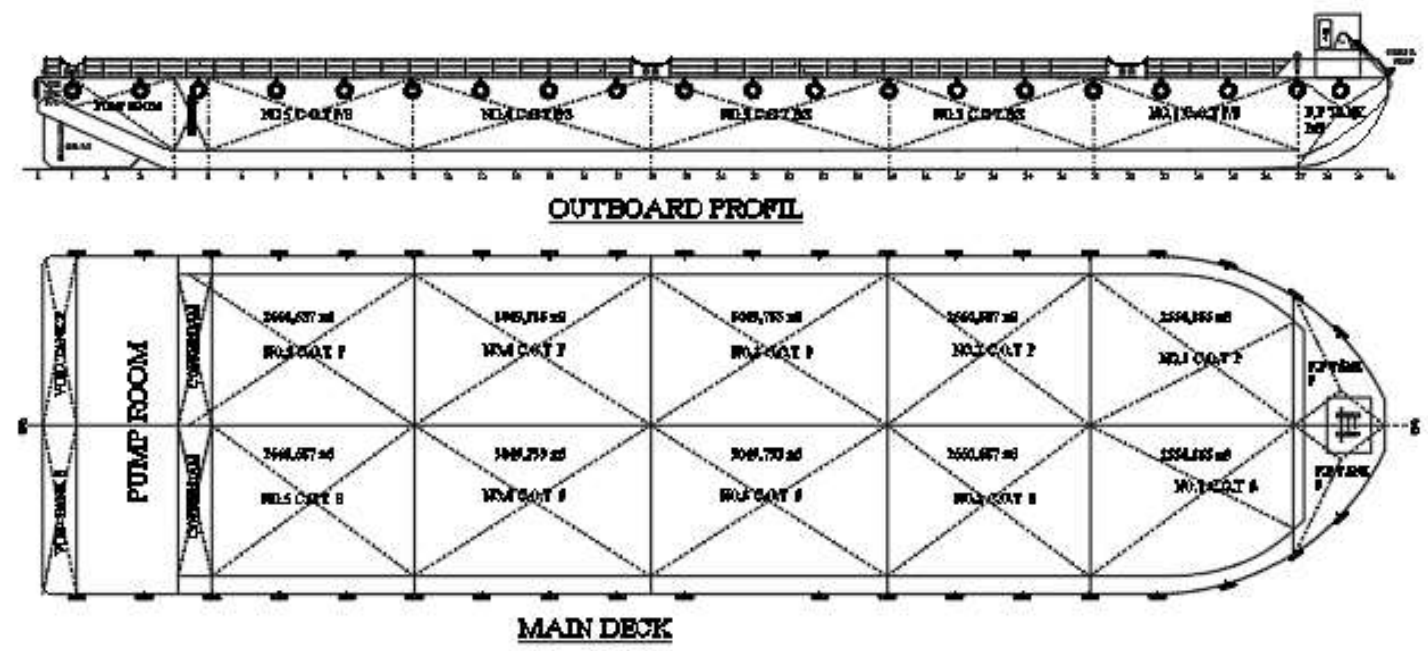

Gambar 2. Desain Sekat Ruang Muat

Selanjutnya dilakukan perhitungan konstruksi ruang muat. Dari hasil perhitungan didapat hasil sebagai berikut:

Tabel 2. Hasil Perhitungan Desain Ruang Muat

\begin{tabular}{lll}
\hline No & Konstruksi & Hasil $(\mathrm{mm})$ \\
\hline 1 & Tinggi Double Bottom & $1000 \mathrm{~mm}$ \\
2 & Tebal Centre Girder & $12 \mathrm{~mm}$ \\
3 & Tebal Side Girder & $12 \mathrm{~mm}$ \\
4 & Tebal Inner Bottom Plate & $16 \mathrm{~mm}$ \\
\hline
\end{tabular}

copyright is published under Lisensi Creative Commons Atribusi 4.0 Internasional. 


\begin{tabular}{lll}
\hline No & Konstruksi & Hasil $(\mathrm{mm})$ \\
\hline 5 & Lebar Double Hull & $1000 \mathrm{~mm}$ \\
6 & Tebal Pelat Sisi Dalam & $12 \mathrm{~mm}$ \\
\hline
\end{tabular}

Berdasarkan hasil dari perhitungan konstruksi ruang muat yang mengacu pada BKI Vol II untuk kapal bermuatan minyak berbahaya harus menggunakan kontruksi lambung double bottom dan double hull. Konstruksi oil barge tersebut sudah ditambahkan untuk double hull 1 meter dari pelat terluar dan double bottom setinggi 1 meter dari bottom. Dari hasil perhitungan tersebut sudah sesuai dengan klas BKI dan nantinya bisa digunakan sebagai acuan penelitian berikutnya yang berhubungan dengan konstruksi kapal tanker ataupun kapal cargo. Setelah dilakukan perhitungan konstruksi ruang muat selanjutnya dilakukan desain perencanaan 2 dimensi menggunakan software AutoCAD 2018. Berikut hasil desain perencanaan 2 dimensi dapat dilihat pada gambar 3

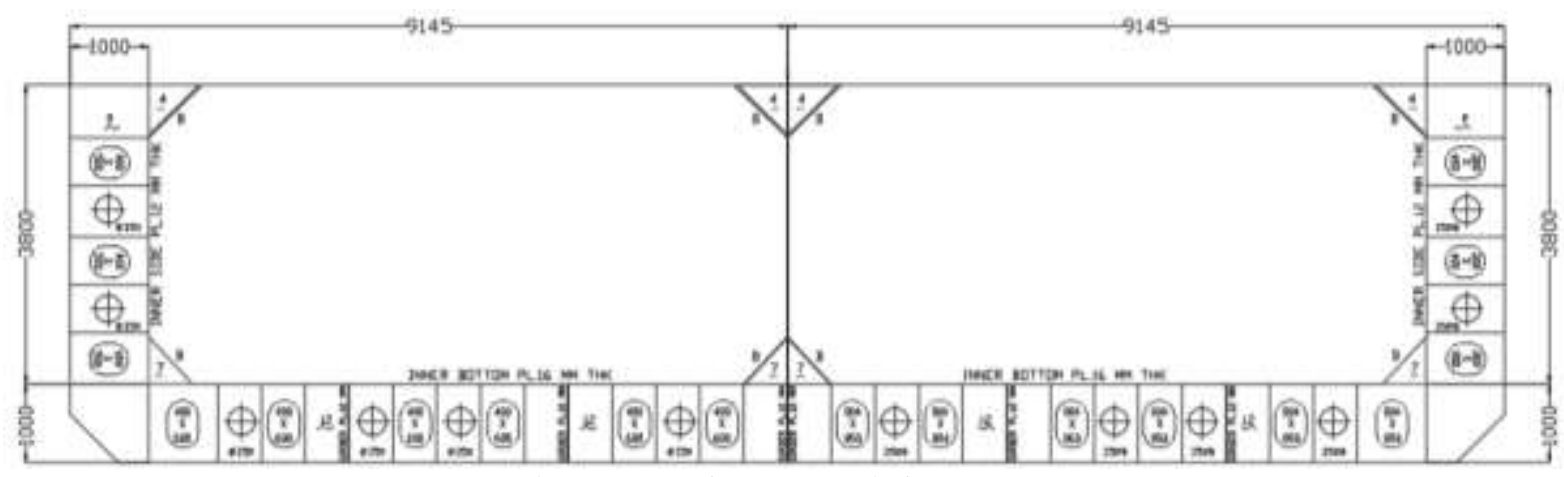

Gambar 3. Desain Konstruksi Ruang Muat

Pada tahap selanjutnya dilakukan perhitungan dan desain sistem bongkar muat yaitu menentukan diameter pipa, kapasitas pompa, headloss untuk menentukan daya pompa cargo dan stripping. Kemudian setelah mendapatkan spesifikasi penulis melakukan desain sistem bongkar muat yang mengacu pada rules BKI Vol III tentang instalasi jalur pipa cargo. Dari hasil perhitungan didapat hasil sebagai berikut :

Tabel 4. Hasil Perhitungan Sistem Bongkar Muat

\begin{tabular}{cll}
\hline No & Konstruksi & Hasil Perhitungan \\
\hline 1 & Diameter Pipa Pompa Utama & $150 \mathrm{~mm}$ \\
2 & Kapasitas Pompa Utama & $336 \mathrm{~m}^{3} / \mathrm{hr}=0,093 \mathrm{~m}^{3} / \mathrm{s}$ \\
3 & Daya Pompa Utama & $44,73 \mathrm{Kw}$ \\
4 & Kapasitas Pompa Standby & $168 \mathrm{~m}^{3} / \mathrm{hr}=0,046 \mathrm{~m}^{3} / \mathrm{s}$. \\
5 & Daya Pompa Standby & $22,36 \mathrm{Kw}$ \\
6 & Diameter Pipa Stripping Pump & $65 \mathrm{~mm}=2,55 \mathrm{Inch}$ \\
7 & Kapasitas Pompa Utama Stripping & $50,4 \mathrm{~m}^{3} / \mathrm{hr}=0,014 \mathrm{~m}^{3} / \mathrm{s}$ \\
8 & Daya Pompa Stripping & $16,96 \mathrm{Kw}$ \\
9 & Kapasitas Pompa Standby Stripping & $25,2 \mathrm{~m}^{3} / \mathrm{hr}=0,007 \mathrm{~m}^{3} / \mathrm{s}$ \\
10 & Daya Pompa Standby Stripping & $8,480 \mathrm{KW}$ \\
\hline
\end{tabular}

Setelah dilakukan perhitungan system bongkar muat selanjutnya dilakukan desain perencanaan 2 dimensi menggunakan software AutoCAD 2018. Berikut hasil desain perencanaan 2 dimensi dapat dilihat pada gambar 4. 


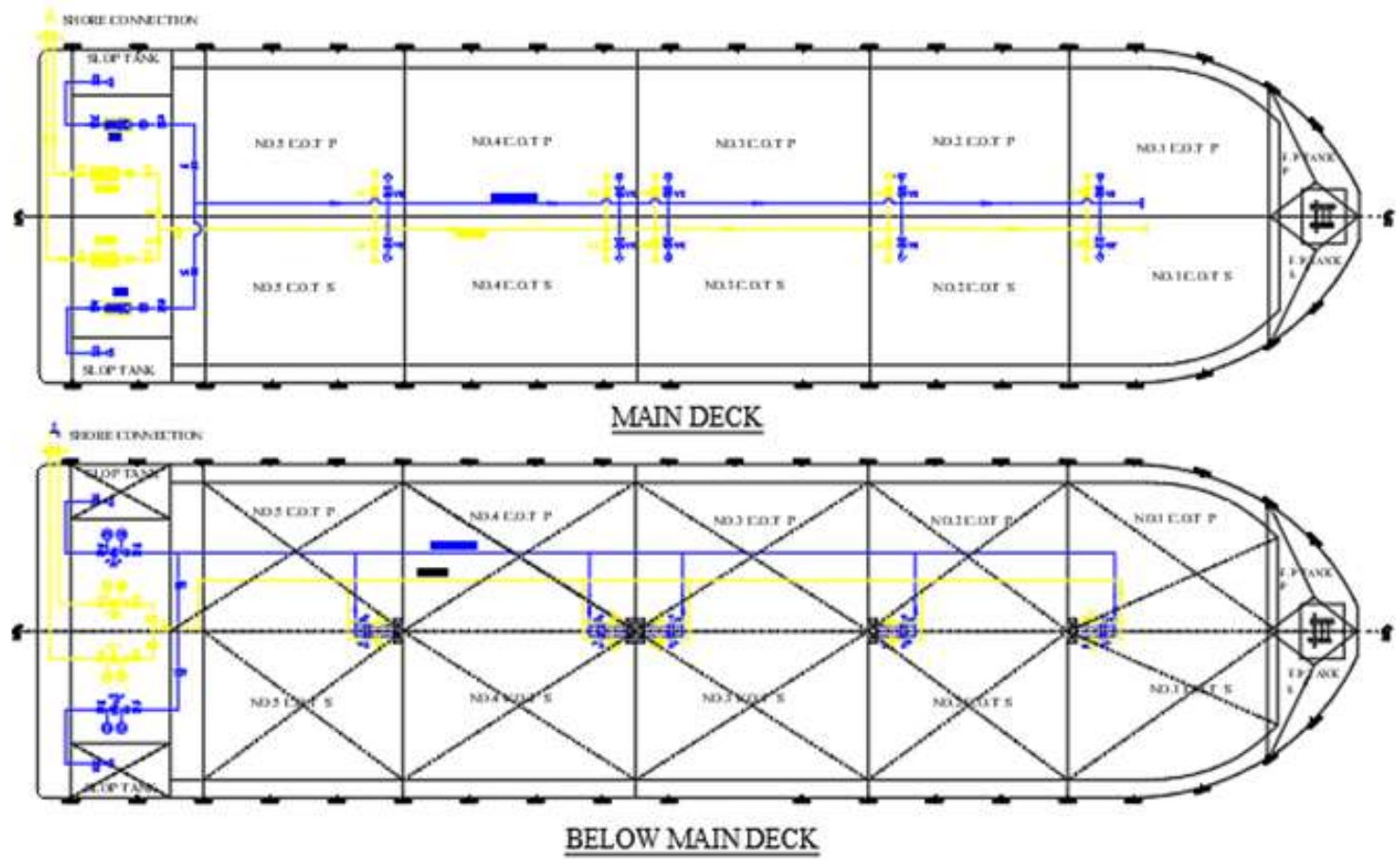

Gambar 4. Diagram Perpipaan Sistem Bongkar Muat

\section{KESIMPULAN}

Berdasarkan hasil pembahasan, analisa data, dan perhitungan yang sudah dilakukan maka dapat diambil kesimpulan sebagai berikut :

1. Hasil perencanaan desain ruang muat dengan menggunakan standart perhitungan BKI didapatkan 5 ruang muat dengan masing-masing ukuran ruang muat yaitu : ruang muat 1 dan 2 didapat kan panjang 10.980 $\mathrm{mm}$, ruang muat 3 dan 4 didapat kan panjang $12.810 \mathrm{~m}$, ruang muat 5 didapat kan panjang $10.980 \mathrm{~mm}$. Ukuran kontruksi ruang muat dengan tinggi double bottom $1 \mathrm{~m}$,tebal centre girder $12 \mathrm{~mm}$, tebal side girder $12 \mathrm{~mm}$, tebal pelat alas dalam $16 \mathrm{~mm}$ dan lebar double hull $1 \mathrm{~m}$, tebal pelat sisi dalam $12 \mathrm{~mm}$.

2. Berdasarkan perencanaan pada sistem bongkar muat bahwa : volume tangki total $8340,003 \mathrm{~m} 3$, diameter pipa direncanakan $150 \mathrm{~mm}$, kapasitas 2 pompa utama bongkar muat yaitu $336 \mathrm{~m} 3 / \mathrm{hr}=0,093 \mathrm{~m} 3 / \mathrm{s}$ dengan waktu $12 \mathrm{jam}$, kapasitas pompa standby bongkar muat yaitu $168 \mathrm{~m} 3 / \mathrm{hr}=0,046 \mathrm{~m} 3 / \mathrm{s}$, daya pompa utama $44,73 \mathrm{Kw}$, daya pompa standby $22,365 \mathrm{Kw}$, main stripping pump, diameter pipa direncanakan $65 \mathrm{~mm}$, kapasitas pompa utama stripping yaitu $50,4 \mathrm{~m} 3 / \mathrm{hr}=0,014 \mathrm{~m} 3 / \mathrm{s}$, daya pompa $16,96 \mathrm{Kw}$, standby stripping pump, diameter pipa direncanakan $65 \mathrm{~mm}$, kapasitas pompa standby stripping yaitu $25,2 \mathrm{~m} 3 / \mathrm{hr}=0,007$ $\mathrm{m} 3 / \mathrm{s}$, daya pompa $8,480 \mathrm{Kw}$.

\section{UCAPAN TERIMA KASIH}

Terima kasih yang sebesar besarnya kepada Lembaga Penelitian dan Pengabdian Masyarakat dan Program Studi Teknik Sistem Perkapalan Fakultas Teknik Universitas Hang Tuah atas pendanaan penelitian ini.

\section{DAFTAR PUSTAKA}

[1] N. Samson, E. Ogbonnaya, and K. Ejabefio, "Stability Analysis for the Design of 5000-Tonnes Offshore Work Barge," vol. 3, no. 9, pp. 849-857, 2013.

[2] W. Barge, "Calculation for Hull Strength Construction in Offshore Structures (A Case Study of 5000t Work Barge)," West African J. Ind. Acad. Res., vol. 8, no. 1, pp. 3-12, 2013. 
[3] A. Ramadhan et al., "Analisa Kekuatan Konstruksi Double Bottom Pada Frame 46 Sampai Frame 50 Akibat Perubahan Dari Single Hull Ke Double Hull Pada Kapal Tanker 13944 Ltdw Dengan Metode Elemen Hingga," J. Tek. Perkapalan, vol. 4, no. 4, pp. 858-867, 2016.

[4] B. K. Indonesia, "Pedoman Lambung Edisi 2016 Biro Klasifikasi Indonesia," vol. 2, 2016. 